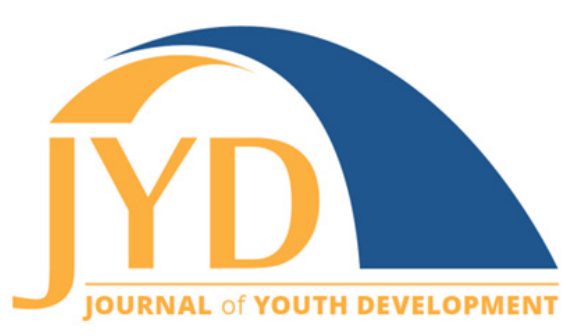

http://jyd.pitt.edu/ | Vol. 12 Issue 4 DOI 10.5195/jyd.2017.520 | ISSN 2325-4017 (online)

\title{
Youth-Adult Partnerships in Work with Youth: An Overview
}

\author{
Heather L. Ramey \\ Humber College, Brock University, Centre of Excellence for Youth Engagement \\ heather.ramey@humber.ca
}

Heather L. Lawford

Bishop's University, Brock University, Centre of Excellence for Youth Engagement

hlawford@ubishops.ca

Wolfgang Vachon

Child \& Youth Care Program, Humber College

wolfgang.vachon@humber.ca

\begin{abstract}
Youth-adult partnerships in child and youth services engage the participants in collaborative, shared decision making, in areas such as governance, program planning and implementation, and advocacy. However, these partnerships often occur in isolation, and fail to engage in potentially useful, larger conversations about theory and research. Therefore, in an effort to provide common grounds for understanding and engaging in such partnerships, we offer an overview of current literature. We discuss definitions and discourses, describe models of youth-adult partnerships, and briefly consider current research on potential benefits for youth, adults, organizations, and communities. We also present challenges and promising practices for adult allies engaged in youth-adult partnerships.
\end{abstract}

Key words: youth-adult partnership, youth engagement, youth voice, adult ally, youth work

\section{Introduction}

Youth-adult partnerships in child and youth services situate young people as valued coparticipants in systems that have traditionally treated youth as recipients, by engaging youth and adults in collaborative decision making (Dupuis \& Mann-Feder, 2013). Some of the services that have tended to promote youth-adult partnerships are public and mental health services, youth drop-ins, and recreation and community centers (Zeldin, Christens, \& Powers, 2013).

(cc) EY New articles in this journal are licensed under a Creative Commons Attribution 4.0 License. This journal is published by the University Library System, University of Pittsburgh and is cosponsored by the University of Pittsburgh Press. The Journal of Youth Development is the official peer-reviewed publication of the National Association of Extension 4-H Agents and the National AfterSchool Association. 
Youth-Adult Partnerships in Work with Youth

Across various settings, youth can be engaged in governance, program planning and implementation, advocacy, or a range of other roles.

Although some research suggests that youth-adult partnerships are relatively common (e.g., Akiva, Cortina, \& Smith, 2014), these partnerships appear to occur in isolation from one another, and at times without apparent foundation in current research literature. There are a number of examples in recent literature and practice manuals that do not reference existing definitions and frameworks (e.g., Pancer, Rose-Krasnor, \& Loiselle, 2002; Rose-Krasnor, 2009; Zeldin et al., 2013), perhaps due to the cross-disciplinary nature of youth-adult partnerships.

To establish grounds for more unified efforts by researchers and practitioners, we herein offer an overview of themes in literature and research on youth-adult partnerships, as they apply to direct work with young people, within a North American context. We begin with current definitions and language about youth-adult partnerships, then characterize the settings where youth-adult partnerships might occur, and describe models of and rationales for youth-adult partnerships. We then briefly consider current research on potential benefits for youth and adults, and the organizational and community contexts of youth-adult partnerships. Finally, we discuss challenges and promising practices that arise from current literature on youth-adult partnerships. This review is meant to be useful to all stakeholders in the area of youth work, to offer a brief overview of the research literature as well as discuss some of the current conversations and controversies that are currently taking place in the literature.

\section{Defining Youth-Adult Partnerships in Youth Work}

In research articles and gray literature (e.g., published program reports) on youth-adult partnerships, a number of key terms can be found, including youth-adult partnerships, youth engagement, and adult allies (e.g., Pereira, 2007; Zeldin et al., 2013). Youth-adult partnership, a term used by some researchers, has recently been defined as "the practice of: (a) multiple youth and multiple adults deliberating and acting together, (b) in a collective [democratic] fashion (c) over a sustained period of time, (d) through shared work, (e) intended to promote social justice, strengthen an organization and/or affirmatively address a community issue" (Zeldin et al., 2013, p. 388). Zeldin and colleagues (2013) state that this definition is grounded in the "historical, community, and empirical foundations" of youth-adult partnership (p. 388), integrates the interpersonal nature of youth-adult partnership, applies across disciplines (e.g., psychology, civic engagement), and can be used across a variety of contexts. 


\section{Youth-Adult Partnerships in Work with Youth}

In practice and in services for young people, youth engagement is the term perhaps most frequently used to refer to youth-adult partnerships (e.g., ACT for Youth Center of Excellence, 2017; Saito \& Sullivan, 2011). Youth engagement has been defined as sustained, meaningful participation in an activity outside of the self (Pancer et al., 2002). In addition to the term youth engagement, other phrases are also used, including youth involvement in decision making, youth voice, youth empowerment, youth mobilization, and youth participation (Ministry of Children and Family Development, 2013). Youth participation is a term used in the United Nations Convention on the Rights of the Child (UNCRC) (The United Nations, 1989). Based on Articles 12 and 15 of the UNCRC, which outline young people's rights to participate in decisionmaking processes relevant to their lives, and to engage in political processes, Checkoway (2011) defined youth participation as "a process of involving young people in the institutions and decisions that affect their lives" (p. 341). Checkoway (2011) further argued that participation in contexts such as community agencies and intergenerational partnerships should be measured not only by scope, but also by quality. He thus added that participation is "the active engagement and real influence of young people, not to their passive presence or token roles in adult agencies" (p. 341).

A number of these terms have come under criticism. Some, such as youth engagement, youth participation, and youth empowerment, are unidirectional, implying a process of adults engaging youth, empowering youth, and evoking youth's participation (Ramey \& Lawford, in press). Dupuis and Mann-Feder (2013) and Shaw-Raudoy and McGregor (2013) have highlighted some of the challenges and subtleties inherent in the use of the terms youth empowerment and youth-adult partnership. For example, Dupuis and Mann-Feder (2013) pointed out that the language of youth empowerment does not fit with the work done in the child welfare system, where adults are responsible for the welfare of the child, and are legally and morally obligated to make choices for them. In these contexts, young people are frequently involuntary recipients of services. Dupuis and Mann-Feder (2013) suggest that, given these circumstances, sweeping cultural changes to child protection would be required for the language of "empowerment" to be meaningful.

Shaw-Raudoy and McGregor (2013) argued that the term youth-adult partnership reinforces boundaries between youth and adults, and therefore reinforces youth as learners and adults as knowledge holders. They suggested that too much focus on youth-to-adult empowerment maintains youth's dependency upon adults, making it impossible for youth to become agents of change in their own right. Following Dupuis and Mann-Feder (2013) and Shaw-Raudoy and McGregor's (2013) arguments, however, none of the terms currently in use appear impervious 
Youth-Adult Partnerships in Work with Youth

to criticism. That is, in any organization that maintains adult-created mandates and structures, equal decision-making power and access to resources might be impossible. Despite limitations, we have adopted the term youth-adult partnership throughout the current paper. We acknowledge that this language might not reflect youth's or adults' experiences of power sharing but is inclusive of the youth and adults in youth-adult partnerships (see Ramey and Lawford [in press] for further discussion).

Adult allies is a term for adults engaged in youth-adult partnerships (e.g., Gordon, 2010; Khanna \& McCart, 2007). Adult allies join in collaborative, equitable, mutual activities with young people (Checkoway, 1996), sharing both power and accountability for the achievements and failures of the partnership (Khanna \& McCart, 2007). Ethnographic research on the role of adult allies in youth social movements suggests that effective adult allies partner with youth, respecting their ideas and abilities, and open up spaces for youth voice in adult spaces, such as non-profit, education, and policy sectors (Gordon, 2016; Taft \& Gordon, 2016).

\section{Settings, Measurement, and Rates of Youth-Adult Partnership}

Youth-adult partnerships occur in a variety of settings related to direct work with youth (Zeldin et al., 2013). These include national organizations, which might support youth projects, training, and conferences (e.g., The Students Commission of Canada, 2016). Youth-adult partnerships also can occur in politics and government, as a form of civic engagement, such as in city youth councils (e.g., Blanchet-Cohen, 2006). Finally, they can occur at local levels and in community organizations, such as youth services, community recreation and leisure organizations, and in youth advocacy. For example, former wards of the state might be engaged in advocacy and mentoring of other young people in care (Snow et al., 2013).

Youth involvement in youth-adult partnerships is multidimensional, as indicated by its measurement in research studies (Ramey, Rose-Krasnor, \& Lawford, 2017; Zeldin, Krauss, Collura, Lucchesi, \& Sulaiman, 2014). Youth's involvement has been measured quantitatively, through youth report (e.g., Ramey et al., 2017). Quantitative dimensions typically include youth voice or, similarly, youth input or ownership (Zeldin et al., 2014), as well as collaborative relationships with adults (e.g., Akiva et al., 2014). At times, researchers have separately described youth's program engagement as a third dimension, involving youth's perceptions of the work as valuable and of themselves as active participants (Ramey et al., 2017). Youth involvement in youth-adult partnerships also has been measured quantitatively through adult report although and at least one study has indicated that youth and adult reports of youth voice 
Youth-Adult Partnerships in Work with Youth

in program decisions were relatively well aligned (Akiva et al., 2014). Qualitative studies of youth involvement have similarly entailed interviews with youth and adults to uncover youth voice and engagement in the target program (e.g., Akiva \& Petrokubi, 2016; Dawes \& Larson, 2011).

Rates of youth involvement in youth-adult partnerships are not readily available. However, Akiva et al. (2014) conducted a survey of almost 1000 youth attending after school programs (average age 11.4) in the United States, in part to explore the prevalence of youth involvement in decision making. They found that almost $80 \%$ of these young people identified that they were involved in decision-making activities in their program. Depending on their role, youth volunteering can be considered a form of youth-adult partnership and, in the United States and Canada, young people consistently have high rates of volunteering, comparable to or higher than older age groups (Sinha, 2015; U.S. Bureau of Labor Statistics, 2016). These numbers suggest that youth-adult partnerships are not uncommon.

\section{Models of Youth-Adult Partnership}

Several models of youth-adult partnerships exist, and can provide a basis for decision-making structures and organizational self-examination. Hart's (1992; 2008) landmark model (Figure 1), which took the form of a ladder, described and categorized children's and youth's participation in formal community programming. Hart's ladder was originally published in 1980, and was republished by UNICEF in 1992. It was intended to raise discussion on effective ways to involve children and youth up to the age of 18 in research, planning, and design of children's environments. Hart argued that, in North America and Europe, children and youth's informal participation with adults and meaningful community activity was limited because of children's and youth's segregation into schools and recreation programs. Hart's model outlined eight "rungs" in total. Five rungs represented meaningful participation: (a) children assigned roles, but kept informed; (b) children consulted and informed; (c) adult-initiated and shared childadult decisions; (d) child-initiated and directed; and (e) child initiated and shared child-adult directed participation. Hart (1992) also included three rungs for non-participation: manipulation, decoration, and tokenism. In tokenistic roles, children and youth appear to have meaningful participation, but actually do not have any opportunity to express their opinions, or their opinions have no influence. Hart (2008) stated that the primary benefit of his model was its utility in helping youth workers and other professionals rethink how they work with children and youth. 
Figure 1. Hart's (1992) Ladder of Participation

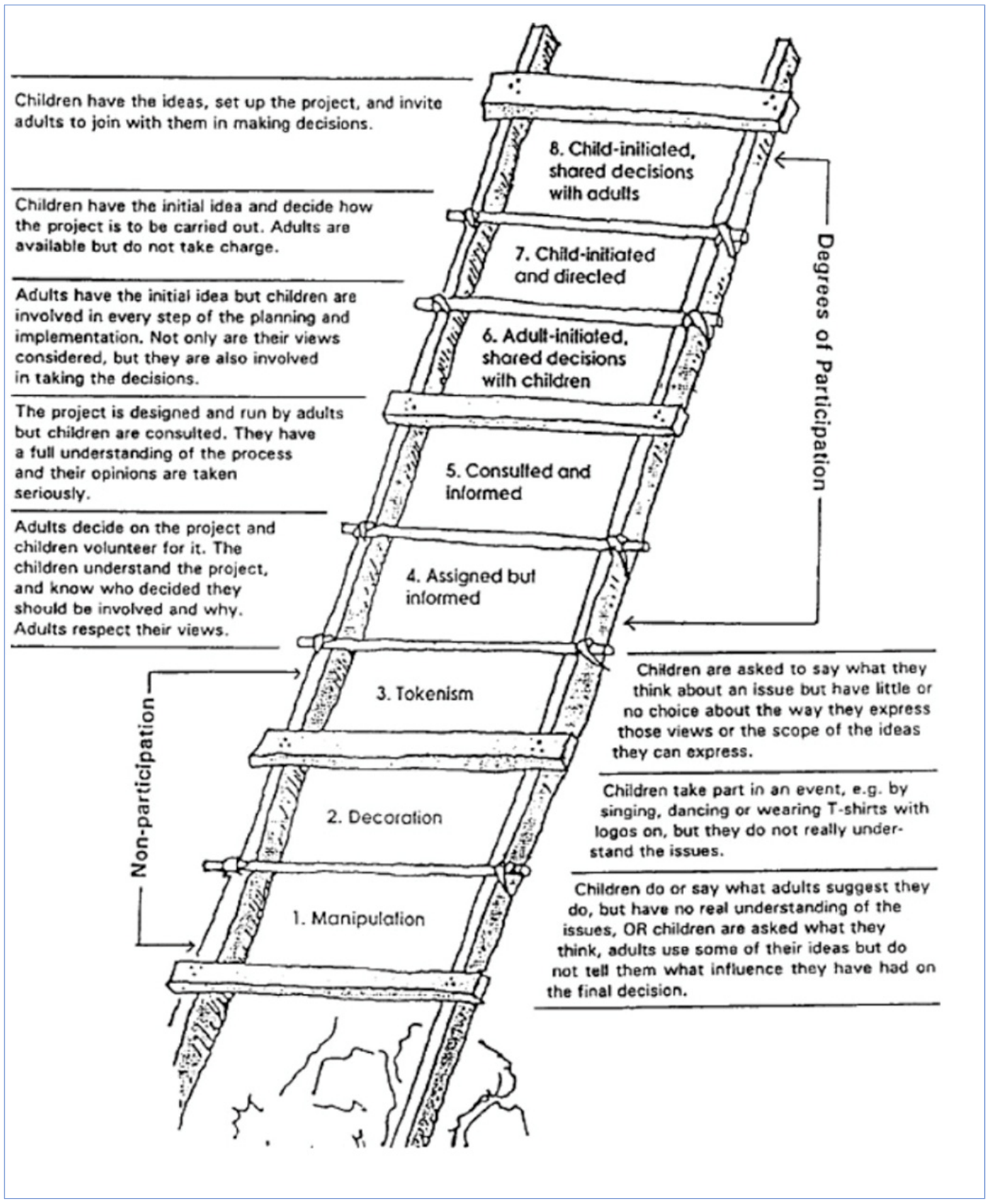

Treseder's (1997; Treseder \& Crowley, 2001) Degrees of Participation model (Figure 2) reconstructed Hart's five levels of participation, shifting them out of a ladder, and into a nonhierarchical frame. Treseder and Crowley (2001) stated that a circular model moved away from the assumption that there is an ideal level of youth participation, as represented by Hart's 
(1992) highest rung. Instead, they argued that young people should have choice regarding their participation, and the appropriate degree of youth's participation should be tailored to the needs of participants, rather than aspiring to any specific ideal. In making this argument, they cite United Kingdom government reports that highlighted the importance of youth's own choice, priorities, and needs regarding their participation. Following Treseder's model, the best level of participation is whichever fits the needs of those involved.

Figure 2. Treseder's (1997) Degrees of Participation (Save the Children)

Consulted and informed The project is designed and run by adults, but children are consulted. They have a full understanding of the process and their opinions are taken seriously.

\section{Child-initiated, shared} decisions with adults Children have the ideas, set up projects and come to adults for advice, discussion and support. The adults do not direct, but offer their expertise for young people to consider.

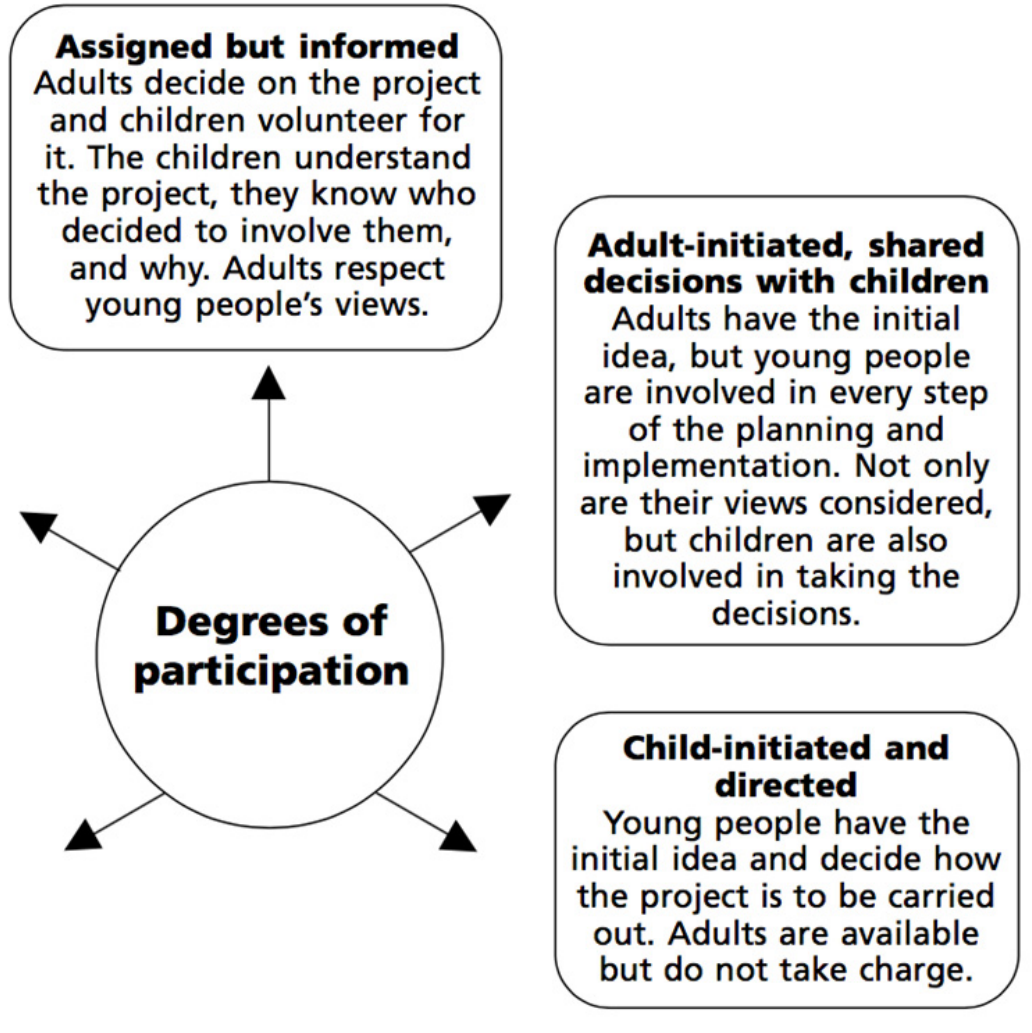

In 2001 Shier proposed a model of participation (Figure 3) based on children's participation rights and the UNCRC. Shier argued that the model, which focuses more on organizational indicators of youth participation than Hart's (1992) model and produces a sequence of questions, provides a more practical tool for organizations. Unlike Hart's model, Shier's model did not include levels of non-participation. Shier's model included five levels: (a) children listened to; (b) children supported in expressing views; (c) children's views taken into account; (d) children involved in decision making; and (e) shared child-adult decision making. Within each of these five levels, Shier included three stages of commitment: openings (e.g., adult 
Youth-Adult Partnerships in Work with Youth

readiness to share power); opportunities (e.g., a procedure for shared power); and obligations (e.g., a policy requirement for shared power). Shier's model highlighted the importance of policies, as formal organizational requirements, emphasizing different aspects of youth participation.

Figure 3. Shier's (2001) Pathways to Participation

\section{Levels of participation \\ Openings >Opportunities >Obligations}

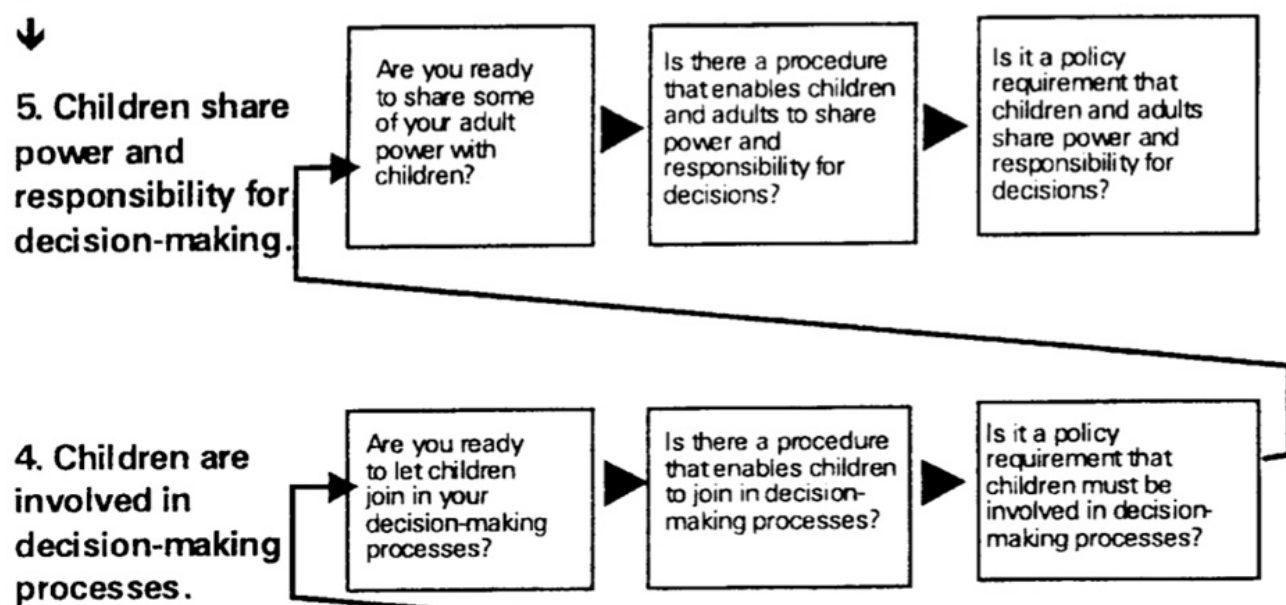

processes.

This point is the minimum you must achieve if you endorse the UN Convertion on the Rights of the Child
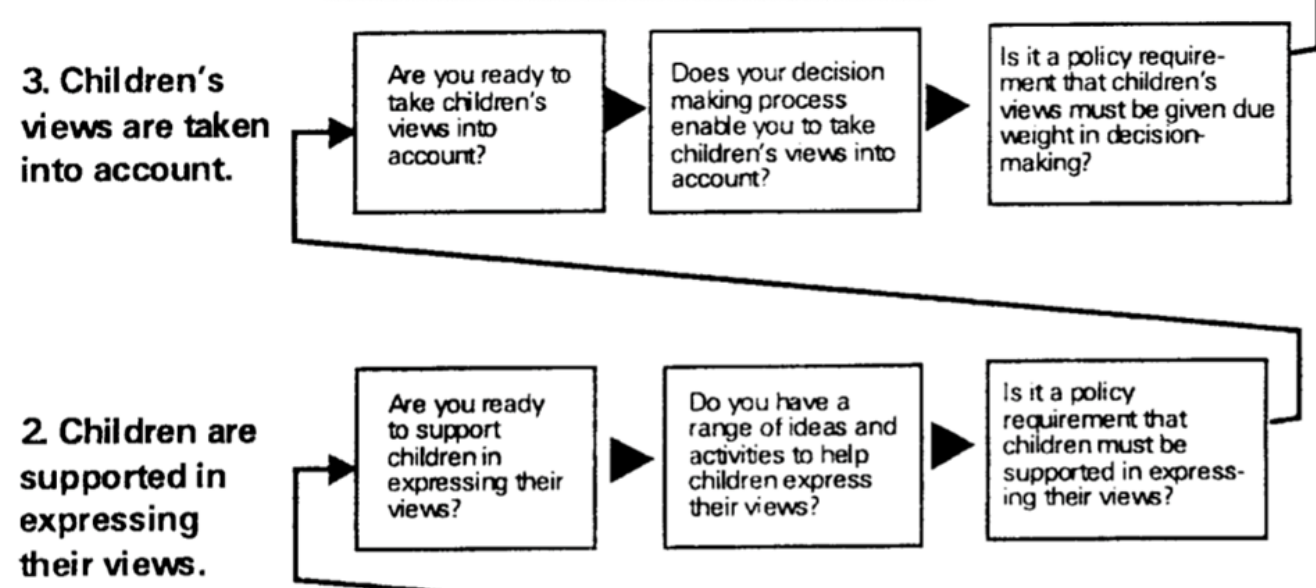

1. Children are listened to. START HERE

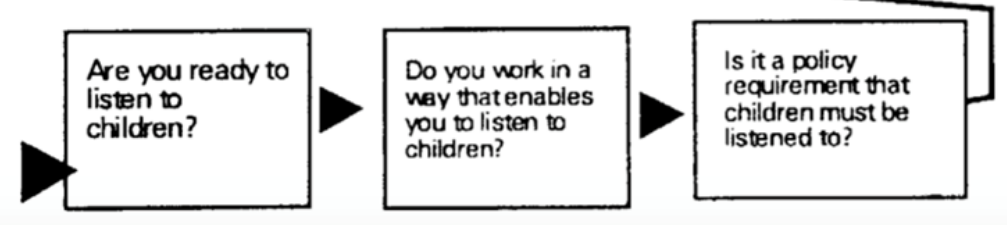


More recently, Wong, Zimmerman, and Parker (2010) presented a model that uses what they describe as an empowerment framework (Zimmerman, 2000). An empowerment framework, as they define it, focuses on shifted control and access to resources, in both its process and outcomes. It also takes into account sociopolitical forces as influencing the quality of people's lives, and requires that individuals become engaged with the organizations and communities that affect their lives. Empowerment thus becomes a process toward shared control as a way to initiate change. In that shared, transactional process, youth and adults bring their own strengths to decision making. Youth's strengths might include culturally specific understandings, and adults' strengths might include experience with organizational practices and procedures. Wong et al.'s Typology of Youth Participation and Empowerment (TYPE) is represented as a pyramid, or inverted "V" (Figure 4). The pyramid is organized as a continuum, with greater adult and less youth control represented on the left, and greater youth and less adult control represented on the right. Shared, "pluralistic" adult-youth control is centered, at the apex of the pyramid. Wong et al. argued that pluralistic control is ideal, based on current research findings regarding youth development and project success.

\section{Figure 4. Wong et al.'s (2010) TYPE Pyramid}

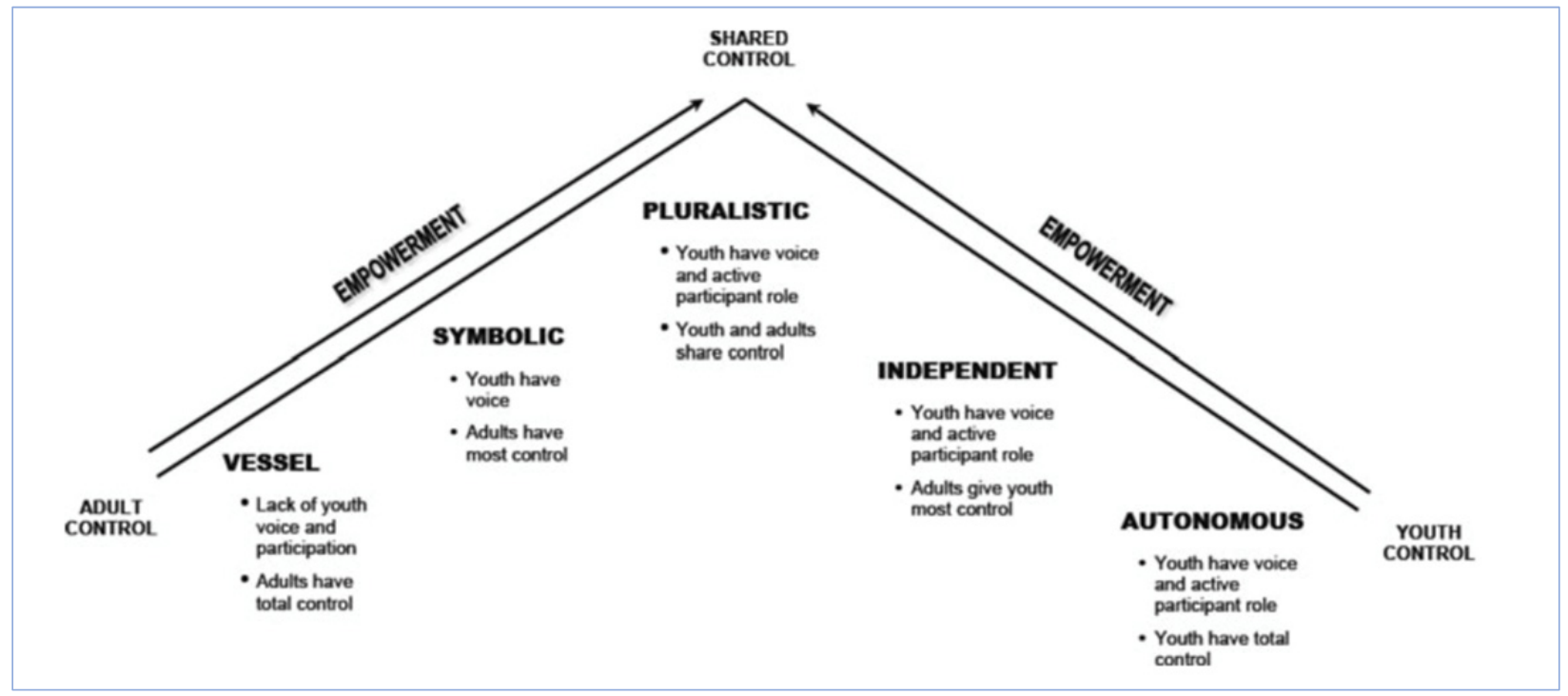

The principal controversy regarding model choice, described by the authors of each of the models, concerns the ideal level of youth and adult decision making and control. The arguments focus on whether all levels are inherently equivalent, compared to a hierarchical framework, and whether youth power is preferable to adult control. Both Hart (2008) and Wong et al. (2010) critiqued models, such as Treseder's (1997), which treat all degrees of participation as 
Youth-Adult Partnerships in Work with Youth

equal. The authors argued that tokenism should not be treated as positive, for example, and that shared youth-adult decisions are clearly better than having children in assigned but informed roles (e.g., Hart, 2008). Hart (2008) defended the location of child-initiated, shared decision making with adults, as the highest rung of the ladder, stating that that the highest degree of citizenship for youth or adults occurs when people recognize the merits of inviting others to join decision-making processes because issues affect them, too. However, Hart (2008) also stated that the appropriate rung of the ladder depends on the age, abilities, and preferences of the child, and the task at hand. In contrast, Wong et al. (2010) argued that models in which youth ideally have primary decision-making power undervalue the contributions of adults and that shared power is ideal for youth empowerment and youth development. The authors stated that research has indicated that initiatives are more likely to be successful (that is, with less struggle, risk, and fewer disempowering outcomes) when there is a high level of support from adults, and that youth require opportunities to develop skills around organizing projects. Wong et al. (2010) further argued that youth and adults each bring different skills to the table, and decision making should be equitable, although it cannot be equal.

Dilemmas regarding the ideal balance of power (i.e., youth-led, adult-led, or shared) in youthadult partnerships are evident not only in discussions of models, but also in empirical literature, and programming. Larson and Walker (2010) described adult allies' dilemmas in knowing when to step back and how to provide guidance without interfering with youth ownership. Larson and Angus (2011) subsequently described the need to provide non-directive assistance or, put differently, to lead from behind. Youth described the need to have some structure and sufficient adult support (e.g., with problem solving), as well as the ability to use adults' access to resources that might be unavailable to youth (Ramey \& Rose-Krasnor, 2015). Research has also, however, pointed to difficulties in getting adults to relinquish their existing power in decision making (Roach, Wureta, \& Ross, 2013).

\section{Rationales for Youth-Adult Partnerships}

\section{Benefits to Youth}

Youth-adult partnerships are hypothesized to benefit youth's development, as youth are engaged in structured activities; developing skills; adopting new roles and responsibilities; building relationships with peers and adults; learning about values and ideals; and taking action on behalf of others (Akiva et al., 2014; Hardy, Pratt, Pancer, Olsen, \& Lawford, 2011; Krauss et al., 2014; Zeldin, Krauss, Kim, Collura, \& Abdullah, 2015). Lawford, Ramey, Rose-Krasnor, and 
Youth-Adult Partnerships in Work with Youth

Proctor (2012) found that youth voice in an activity context, specifically, was related to increases in youth's overall positive development. Depending on youth's roles in the partnership, learning has been reported in areas including leadership, decision making, teamwork, communication, and presentation or public speaking skills (Gambone, Yu, LewisCharp, Sipe, \& Lacoe, 2006; Howe, Batchelor, \& Bochynska, 2011; Ramey \& Rose-Krasnor, 2015). Additional perceived gains in knowledge and understanding have been reported in areas more specific to youth-adult partnership activities, such as knowledge and understanding of youth mental health (Howe et al., 2011; Ramey \& Rose-Krasnor, 2015).

Youth also have been found to develop new friendships through their participation, and to gain interpersonal skills, including learning to listen and work collaboratively with others (Conner, 2014; Howe et al., 2011). Youth involvement in youth-adult partnerships also has been connected to young people's beliefs that they are able to express their thoughts and feelings to others, and to their level of empathy (Akiva et al., 2014). Youth also appear to gain connections at a community level. Krauss et al. (2014) found that supportive youth-adult relationships in youth-adult partnerships were related to greater community connectedness broadly within the community, with both peers and adults. Youth organizing is a specific form of youth-adult partnership focused on advocacy and political change, and appears to have specific benefits. In comparison to traditional youth development programs, youth organizing initiatives have a greater focus on grassroots empowerment and on community change, which tend to focus more on individual youth change (Gambone et al., 2006). Participation in youth organizing has been related to youth's perception that they have greater knowledge of their community, more opportunities to give back, and greater capacity for community problem solving, than through more traditional youth development programs (Gambone et al., 2006).

Youth in youth-adult partnerships have reported additional perceived benefits over the course of their involvement, which Larson and colleagues (e.g., Larson \& Angus, 2011) have argued indicates cognitive and emotional development. They have found that youth report increased self-regulation in focus, attention, and strategic thinking on tasks during their participation (Larson \& Angus, 2011). Youth's skills appear to develop as youth face real-world challenges in youth-adult partnerships (Larson \& Angus, 2011). These challenges require that young people use higher-order thinking to appraise the challenges they are facing, that they maintain their motivation in working toward their goals, and manage emotions, such as anger towards others in the partnership, or disappointment when facing setbacks (Larson, 2011). This process of taking on tasks, experiencing challenge, and maintaining motivation, appears to lead to the development of greater responsibility (Salusky et al., 2014). Relatedly, youth's feelings that they 
Youth-Adult Partnerships in Work with Youth

are engaged in the youth-adult partnership, in particular, also have been linked to identity development (Ramey et al., 2017).

A number of studies indicate that young people have felt empowered by their involvement in youth-adult partnerships, at least in part because their participation was seen as giving them credibility and legitimacy (e.g., Blanchet-Cohen, Manolson, \& Shaw, 2014; Howe et al., 2011). A qualitative study by Cargo, Grams, Ottoson, Ward, and Green (2003) showed that empowerment in youth-adult partnerships occurred though a transactional process, in which adults created a welcoming atmosphere, supporting youth's voice and responsible action. More recently, collaborative youth-adult relationships and youth voice have been related to youth's general levels of empowerment and personal agency, outside of the youth-adult partnership (Krauss et al., 2014). However, youth's perception of empowerment might depend upon the youth-adult partnership model being used, and is more likely to occur in youth-driven rather than adult-driven collaborations (Larson, Walker, \& Pearce, 2005). Greater voice as early as possible in the design phase of projects and partnerships also appears to increase the likelihood of youth's feelings of empowerment (Morciano, Scardigno, Manuti, \& Pastore, 2014).

Research on youth development in youth-adult partnerships suggests that youth derive benefits from both youth-led and adult-led decision making, but that these benefits differ (Larson et al., 2005). Larson et al. (2005) compared an adult-led theatre program and a youth-led program. They found that in the adult-led program, youth learned specific skills related to the project (e.g., voice projection, painting techniques) and also gained self-confidence and interpersonal skills. In the youth-led project, in contrast, youth reported learning leadership skills and reported feeling more empowered.

Potential benefits appear to depend not only on the activities of the youth-adult partnership, but also on the organizational context. For example, Ramey et al. (2017) found that the connection between youth involvement and successful identity was stronger in youth services and recreation centers than in health organizations, suggesting that different types of organizations provide different contexts for youth's development. This suggests that it is not just about the adult(s), or what youth and adults are doing; the broader organization appears to make a difference for youth's development. It is unclear at this point what specific role the organization plays, but among the factors that might make a difference are the integration of youth-adult partnership principles at the broader organizational level (Roach et al., 2013) and ongoing contact with youth as a regular part of organizational practices (Ramey et al., 2017). In 
Youth-Adult Partnerships in Work with Youth

summary, research to date suggests that participating in youth-adult partnerships has benefits for youth development, although it might depend on how and where youth are engaged.

\section{Benefits for Organizations and Society}

The grounds for promoting youth-adult partnerships go beyond the wide-ranging benefits to youth. Youth's contributions to the contexts of their lives, however, and particularly contexts such as organizational settings, appear to have received less attention from researchers than youth's developmental benefits. A review by Ramey (2013) found that youth-adult partnerships were perceived to have benefits for services (e.g., youth programs, recreational and community organizations), adult allies and other staff, and organizations. For services, perceived benefits included more service utilization and greater connection with youth, leading to program improvements. For staff, perceived benefits included increased motivation and confidence. However, it should be noted that involvement in youth-adult partnerships was also perceived to increase stress, in part due to lack of staff training, time, and other resources. Finally, perceived benefits for organizations involved in youth-adult partnerships included positive reputation in the community and improvements in achieving organizational goals. More recent research (Iwasaki et al., 2016) similarly concluded that youth-adult partnerships helped build organizational capacity in community organization settings, strengthening the potential to meet organizational goals.

Youth-adult partnerships also appear to have benefits for broader communities, beyond the boundaries of the youth-adult partnership and the organizational setting. For example, a study of youth-adult partnerships in youth journalism concluded that youth's writing informed their readership, which included both local youth and adults. Articles covered topics, such as abuse against women, that youth saw as important to young people and the larger community (Neely, 2015). Youth also perceived their activities in youth-adult partnerships to change the perceptions of other youth and adults in the community, by demonstrating youth's capacities to make contributions in the community, and by youth serving as role models for others (BlanchetCohen et al., 2014; Neely, 2015).

\section{Building a Civil Society}

A further rationale for participation in youth-adult partnerships is the importance of building a civil society (Zeldin, 2004). In a civil society, organizations and society work better when all 
Youth-Adult Partnerships in Work with Youth

perspectives, including youth's, are represented in governance and problem solving (Zeldin, 2004).

\section{Supporting Youth Rights to Participate}

Youth-adult partnerships are a means of supporting youth's right to participate (The United Nations, 1989). Article 12 of the UNCRC enshrines children and youth's right to participate in all decision-making processes relevant to their lives and to influence decisions affecting them, in accordance with their age and development. In addition, Article 13 states that children have the right to freedom of expression, including seeking, receiving, and sharing information, and Article 15 states that children have the right to freedom of association and peaceful assembly. Checkoway (2011) argued that these articles recognize young people's rights to share perspectives and to participate as decision makers in broader society. Rights to express political opinions, engage in political processes, and participate in decision making require that youth have necessary information about available options and their consequences. These rights also require that youth have opportunities to gain skills and confidence related to these rights, as a prerequisite for informed and free decision making (Checkoway, 2011).

\section{Funding Requirements}

A final rationale is related to funding. Although historically, funding for youth-adult partnerships within the settings of child and youth care has been limited (Blanchet-Cohen, Linds, MannFeder, \& Yuen, 2013; Dupuis \& Mann-Feder, 2013), youth engagement has become a program requirement for some funders, both for established programs or for new funding opportunities (e.g., Laidlaw Foundation, 2016).

\section{Challenges to Implementation}

Researchers have identified several practical challenges to youth-adult partnerships. At youth and adult levels, barriers include constraints on time, as youth balance multiple scheduling demands (Larson \& Walker, 2010). A further barrier is sustaining youth's motivation over time and even when decisions and planning are not successful (Larson \& Walker, 2010). Adult allies have reported the need to manage group dynamics, as youth might challenge group norms and expectations, and to balance structure and guidance with youth ownership over projects (Collins, Augsberger, \& Gecker, 2016; Larson, Walker, Rusk, \& Diaz, 2015). Adults were found to be resistant to sharing power and treating youth as partners (Collins et al., 2016). Youth 
Youth-Adult Partnerships in Work with Youth

were also found to be reluctant to take on decision-making power, out of doubt about their actual levels of control in decision making, as egalitarian relationships with adults fall outside their prior experiences, because of actual lack of power, or experiences of adult resistance (Collins et al., 2016; Roach et al., 2013).

Youth ownership over projects might be presented with constraints at organizational or systemic levels. Smith, Peled, Hoogeveen, Cotman, \& the McCreary Centre Society (2009) found that, once youth had a "seat at the table" in decision making, they could be frustrated by the limits of their decision-making power. Larson et al. (2015) also described adult allies' challenges in interfacing with organizational mandates, and the agencies upon which project funding may depend. A finding by Morgan (2016), that the issues and themes that youth choose to focus on could differ from the agendas of the funding bodies, or even be critical of them, suggest that the nature of engagement sought by funding bodies (e.g., consultation versus shared decision making) should be clarified.

\section{Promising Practices for Implementation}

Research points to a number of promising practices for adults and organizations engaged in youth-adult partnerships. We present several below.

1. Maintain youth at the center of decision making. In response to the need to learn to share power more equitably, as well as to maintain youth's ownership over initiatives, successful adult allies have been found to be youth-centered (Collins et al., 2016; Larson et al., 2015). Experienced adult allies demonstrate the ability to shift dilemmas into opportunities, engaging youth in problem solving around these issues (Larson et al., 2015). For example, adult advice-giving is restrained, and aimed at helping youth succeed in projects, avoiding taking on the role of an authority figure, and supporting youth learning to solve problems on their own (Larson, Izenstark, Rodriguez, \& Perry, 2016).

2. Provide resources, including but not limited to training for youth and adults, support, and time. Practitioners have reported the need for more resources for youthadult partnership work, including training and time (Larson et al., 2015; Ramey, 2013). Youth work practitioner and adult ally roles are not the same (Ramey \& Rose-Krasnor, 2015). Further, youth-adult partnerships might focus on issues with which practitioners lack familiarity (e.g., human rights, environmental issues) (Cooper, Nazzari, Kon Kam 
Youth-Adult Partnerships in Work with Youth

King, \& Pettigrew, 2013), creating the need for topic-specific training. Additionally, adult allies appear to be expected to fit youth-adult partnership work into already busy workloads, creating additional stress (Ramey, 2013). This requires that policies and organizational practices provide sufficient resources and flexibility to support the needs of successful youth-adult partnerships (Heffernan et al., 2017).

\section{Adult allies should view their work through a social justice, anti-oppressive} lens. As reflected in the definition of youth-adult partnerships, as involving involve youth and adults acting collectively in social justice, organizational or community work (Zeldin et al., 2013), the concept of ally contains a social justice agenda. This explicit awareness of the socio-cultural systems of oppression that impact young people can be absent in other forms of work with youth. To be an ally is to engage actively towards ending oppressions. In writing of being allies outside of youth social services, some advocates have stated that members of the privileged group need to take direction from the oppressed group, as the oppressed understand their oppression better than the oppressor (e.g., Bishop, 2015). A phrase from disability studies (and disability activists), which has been adopted by some people working with children and youth (Vachon \& McConnell, in press) is "nothing about us without us." This framing of working with young people requires adult allies to understand the historical and current oppression of young people, and how adults have contributed to this oppression. Further, adult allies need to know how to take direction from young people, while simultaneously integrating and supporting the many elements required for effective youth-adult partnerships. We note that this understanding of "allyship" might pose challenges to seeing the relationship(s) as shared, equitable, and mutual, and potentially moves away from youth-adult partnership and more towards what Hart (1992) identified as youth-initiated and directed.

\section{Integrate the principles underlying youth-adult partnerships across the} broader organization. A challenge exists in the realm of organizational culture, where governance and agendas are adult driven (Cooper et al., 2013; Roach et al., 2013). This might be attributable to the reality that in many organizations, youth-adult partnerships are an additional aspect of some programs, or exist as stand-alone programs within larger organizations (e.g., Heffernan et al., 2017). Blanchet et al. (2013) argued that youth's engagement in youth-adult partnership should be extended "beyond a mere trend or project, to constitute a value system that underlies practice" (p. 321). Roach et 
Youth-Adult Partnerships in Work with Youth

al. (2013) argued that the principles underlying authentic youth-adult partnerships need to be integrated broadly across the organizations.

5. Engage the broader community. Successful youth-adult partnerships engage the broader community. The community is an important context of youth's lives, and youth should therefore be engaged in community decision making (Checkoway, 2011). For many organizations, too, achievement of program goals is strengthened by engaging the broader community, as community engagement furthers advocacy work, and engages larger numbers of youth in the work of the youth-adult partnership (Ramey, 2013).

6. Demonstrate an actual effect, through program evaluation. Successful youthadult partnerships demonstrate a real effect over decisions, process, and/or outcomes (Checkoway, 2011). Youths' and adults' perception that substantive change is occurring appears to be important in contributing to youths' and adults' sense of empowerment, and add to the belief that the partnership is meaningful (Collins et al., 2016; Cooper et al., 2013). Demonstrating an actual effect requires evaluation. Moreover, evaluation should be implemented at program onset, rather than as an afterthought (Arnold, Cater, \& Braverman, 2017).

\section{Consider the unique needs of specific youth-adult partnerships and interest} areas. Specific contexts require their own considerations. For example, Howe et al. (2011) found that practitioners in a children's mental health organization with a youthadult partnership had concerns pertaining to youth's presence and roles while in the physical office space, and confidentiality regarding current clients. This suggests that, in these specific settings, youth-adult partnerships also require open communication and planning to address concerns regarding boundaries and confidentiality. All partnerships must consider their own unique needs regarding the form of the youth-adult partnership. This includes the choice of models, and agreement in how decision making is shared among youth and adults. Such agreement requires ongoing communication, to ensure that models and decision-making processes continue to be effective (e.g., see Ramey \& Rose-Krasnor, 2015).

\section{Conclusion}

In this paper, we provided an overview of youth-adult partnerships, in a primarily North American context. Youth-adult partnerships are an increasingly important area for practice and research in the field of youth development, with value for youth and adults. Despite significant 
Youth-Adult Partnerships in Work with Youth

pressure to involve youth in decision making, there are limited best practices available for practitioners to follow. To address this gap, we have herein provided a cross-disciplinary overview of some key issues and relevant findings in youth-adult partnerships as a reference.

We reviewed current definitions, and described existing youth-adult partnership models and rationales for youth-adult partnerships. We reviewed research on benefits as well as challenges, and end with recommendations for researchers and practitioners. Taken together, research indicates that youth-adult partnerships should maintain youth at the center of decision making, provide sufficient resources, integrate youth-adult partnership throughout the larger organization and engage the broader community, operate through a social justice lens, evaluate program effectiveness, and address the unique needs of each youth-adult partnership. Integrating youth-adult partnerships throughout the organization; taking a critical, social justice approach; and establishing program effects might be areas particularly in need of focus by existing organizations and peer-reviewed literature (e.g., see Arnold et al., 2017). We hope that, when organizations engage in partnership, they can use existing literature as a basis for their work, and find models and practices that will work for their organizations.

\section{References}

ACT for Youth Center of Excellence. (2017). What is Youth Engagement, Really? Ithaca, NY: Cornell University Bronfenbrenner Center for Translational Research. Retrieved from http://www.actforyouth.net/youth_development/engagement/

Akiva, T., Cortina, K. S., \& Smith, C. (2014). Involving youth in program decision-making: How common and what might it do for youth? Journal of Youth and Adolescence, 43, 1844-1860. doi: 10.1007/s10964-014-0183-y

Akiva, T., \& Petrokubi, J. (2016). Growing with youth: A lifewide and lifelong perspective on youth-adult partnership in youth programs. Children and Youth Services Review, 69, 248-258. doi: 10.1016/j.childyouth.2016.08.019

Arnold, M. E., Cater, M., \& Braverman, M. T. (2017). Rethinking evaluation capacity in youth development programs. In K. M. Possoboni \& B. Kirshner (Eds.), The changing landscape of youth work (pp. 193-209). Charlotte, NC: IAP.

Bishop, A. (2015). Becoming an ally: Breaking the cycle of oppression in people (3rd ed.). Black Point, NS: Fernwood Publishing.

Blanchet-Cohen, N. (2006). Young people's participation in Canadian municipalities: Claiming meaningful space. Canadian Review of Social Policy, 57, 71-84. 
Journal of Youth Development | http://jyd.pitt.edu/ | Vol. 12 Issue 4 DOI 10.5195/jyd.2017.520

Youth-Adult Partnerships in Work with Youth

Blanchet-Cohen, N., Linds, W., Mann-Feder, V., \& Yuen, F. (2013). Introduction to the special issue on transforming practices: Emancipatory approaches to youth engagement. International Journal of Child, Youth and Family Studies, 3, 320-327.

Blanchet-Cohen, N., Manolson, S., \& Shaw, K. (2014). Youth-led decision making in community development grants. Youth \& Society, 46, 819-834. doi: 10.1177/0044118X12455024

Cargo, M., Grams, G. D., Ottoson, J. M., Ward, P., \& Green, L. W. (2003). Empowerment as fostering positive youth development and citizenship. American Journal of Health Behavior, 27, S66-S79.

Checkoway, B. (1996). Adults as allies. Ann Arbor, MI: School of Social Work at the University of Michigan.

Checkoway, B. (2011). What is youth participation? Children and Youth Services Review, 33, 340-345. doi: 10.1016/j.childyouth.2010.09.017

Collins, M. E., Augsberger, A., \& Gecker, W. (2016). Youth councils in municipal government: Examination of activities, impact and barriers. Children and Youth Services Review, 65, 140-147. doi: 10.1016/j.childyouth.2016.04.007

Conner, J. (2014). Lessons that last: Former youth organizers' reflections on what and how they learned. Journal of the Learning Sciences, 23, 447-484. doi: 10.1080/10508406.2014.928213

Cooper, A., Nazzari, V., Kon Kam King, J., \& Pettigrew, A. (2013). Speaking rights: Youth empowerment through a participatory approach. International Journal of Child, Youth and Family Studies, 4(3.1), 489-501.

Dawes, N. P., \& Larson, R. (2011). How youth get engaged: Grounded-theory research on motivational development in organized youth programs. Developmental Psychology, 47, 259-269. doi:10.1037/a0020729

Dupuis, J. \& Mann-Feder, V. (2013). Moving towards emancipatory practice: Conditions for meaningful youth empowerment in child welfare. International Journal of Child, Youth and Family Studies, 3, $371-380$.

Gambone, M. A., Yu, H. C., Lewis-Charp, H., Sipe, C. L., \& Lacoe, J. (2006) Youth organizing, identitysupport, and youth development agencies as avenues for involvement. In B. N. Checkoway \& L. M. Gutiérrez (Eds.), Youth participation and community change (pp. 235-253). New York, NY: Haworth Press.

Gordon, H. R. (2010). We fight to win: Inequality and the politics of youth activism. New Brunswick: Rutgers University Press.

Gordon, H. R. (2016). Between radical possibilities and modest reforms: The precarious position of adult allies in youth movements for racial justice. In M. Heathfield \& D. Fusco (Eds.), Youth and inequality in education: Global actions in youth work (pp. 196-212). New York, NY: Routledge. 
Youth-Adult Partnerships in Work with Youth

Hardy, S. A., Pratt, M. W., Pancer, S. M., Olsen, J. A., \& Lawford, H. L. (2011). Community and religious involvement as contexts of identity change across late adolescence and emerging adulthood. International Journal of Behavioral Development, 35, 125-135. doi: 10.1177/0165025410375920

Hart, R. (1992). Children's participation: From tokenism to citizenship (no. 4). Florence, Italy: UNICEF International Child Development Centre.

Hart, R. (2008). Stepping back from 'The Ladder': Reflections on a model of participatory work with children. In A. Reid, B. B. Jensen, J. Nikel, \& V. Simovska (Eds.), Participation and learning: Perspectives on education and the environment, health and sustainability (pp. 19-31). Dordrecht: Springer Netherlands.

Heffernan, O. S., Herzog, T. M., Schiralli, J. E., Hawke, L. D., Chaim, G., Henderson, J. L. (2017). Implementation of a youth-adult partnership model in youth mental health systems research: Challenges and successes. Health Expectations. Advance online printing.

Howe, D., Batchelor, S., \& Bochynska, K. (2011). Finding our way: Youth participation in the development and promotion of youth mental health services on the NSW Central Coast. Advances in Mental Health, 10, 2-28.

Iwasaki, Y., Dashora, P., McHugh, T.-L., McLaughlin, A.-M., Springett, J., \& Youth4YEG Team. (2016). Reflections on the opportunities and challenges of youth engagement: Youth and professional perspectives. Engaged Scholar Journal, 1, 36-57.

Khanna, N., \& McCart, S. (2007). Adult allies in action. Toronto, ON: Centre of Excellence for Youth Engagement.

Krauss, S. E., Collura, J., Zeldin, S., Ortega, A., Abdullah, H., \& Sulaiman, A. H. (2014). Youth-adult partnership: Exploring contributions to empowerment, agency and community connections in Malaysian youth programs. Journal of Youth \& Adolescence, 43, 1550-1562. doi: 10.1007/s10964-013-0027-1

Laidlaw Foundation (2016). Apply for a grant. Retrieved from http://laidlawfdn.org/fundingopportunities/apply-for-a-grant/

Larson, R. W. (2011). Adolescents' conscious processes of developing regulation: Learning to appraise challenges. New Directions for Child and Adolescent Development, 133, 87.

Larson, R. W., \& Angus, R. M. (2011). Adolescents' development of skills for agency in youth programs: Learning to think strategically. Child Development, 82, 277-294.

Larson, R. W., Izenstark, D., Rodriguez, G., \& Perry S. C. (2016). The art of restraint: How experienced program leaders use their authority to support youth agency. Journal of Research on Adolescence, 26, 845-863. doi: 10.1111/jora.12234

Larson R. W., \& Walker, K. C. (2010). Dilemmas of practice: Challenges to program quality encountered by youth program leaders. American Journal of Community Psychology, 45, 338-349. doi: $10.1007 / \mathrm{s} 10464-010-9307-\mathrm{z}$ 
Larson, R. W., Walker, K. C., Rusk, N., \& Diaz, L. B. (2015). Understanding youth development from the practitioner's point of view: A call for research on effective practice. Applied Developmental Science, 19, 74-86. doi: 10.1080/10888691.2014.972558

Larson, R., Walker, K. C., \& Pearce, N. (2005) A comparison of youth-driven and adult-driven youth programs: balancing inputs from youth and adults. Journal of Community Psychology, 33, 57-74. doi: 10.1002/jcop.20035

Lawford, H. L., Ramey, H. L., Rose-Krasnor, L., \& Proctor, A. (2012). Predictors of adolescent successful development after an exchange: The importance of activity qualities and youth input. Journal of Adolescence, 35, 1381-1391. doi: 10.1016/j.adolescence.2012.05.008

Ministry of Children and Family Development. (2013). Youth engagement toolkit resource guide. Victoria, BC: Ministry of Children and Family Development and University of Victoria School of Child and Youth Care. Retrieved from http://www.mcf.gov.bc.ca/youth_engagement/pdf/yet_resource_guide.pdf

Morciano, D., Scardigno, A.F., Manuti, A., \& Pastore, S. (2014). An evaluation study of youth participation in youth work: A case study in Southern Italy. Educational Research for Policy and Practice, 13, 81-100. doi: 10.1007/s10671-013-9150-8.

Morgan, J. (2016). Participation, empowerment and capacity building: Exploring young people's perspectives on the services provided to them by a grassroots NGO in sub-Saharan Africa. Children and Youth Services Review, 65, 175-182.

Neely, J. C. (2015). Building voices: Teens connect to their communities through youth journalism websites. International Journal of Communication, 9, 2306-2325.

Pancer, S. M., Rose-Krasnor, L., \& Loiselle, L. D. (2002). Youth conferences as a context for engagement. New Directions for Youth Development, 96, 47-63.

Pereira, N. (2007). Ready . . . set . . . engage! Building effective youth-adult partnerships for a stronger child and youth mental health system. Toronto: Children's Mental Health Ontario \& Ottawa: Provincial Centre of Excellence for Child and Youth Mental Health.

Ramey, H. L. (2013). Organizational outcomes of youth involvement in organizational decision-making: A synthesis of qualitative research. Journal of Community Psychology, 41, 488-504. doi: 10.1002/jcop. 21553

Ramey, H. L., \& Lawford, H. L. (in press). From programming to partnering: The evolution of youth engagement. In P. Alldred, F. Cullen, K. Edwards, \& D. Fusco (Eds.), The SAGE Handbook of Youth Work Practice. SAGE.

Ramey, H. L., \& Rose-Krasnor, L. (2015). The New Mentality: Youth-adult partnerships in a community mental health promotion program. Children and Youth Services Review, 50, 28-37. doi: 10.1016/j.childyouth.2015.01.006 
Youth-Adult Partnerships in Work with Youth

Ramey, H. L., Rose-Krasnor, L., \& Lawford, H. L. (2017). Youth-adult partnerships and youth identity style. Journal of Youth and Adolescence, 46, 442-453. doi: 10.1007/s10964-016-0474-6

Roach, J., Wureta, E., \& Ross, L. (2013). Dilemmas of practice in the ecology of emancipatory youthadult partnerships. International Journal of Child, Youth \& Family Studies, 4, 475-488.

Rose-Krasnor, L. (2009). Future directions in youth involvement research. Social Development, 18, 497509.

Saito, R. N., \& Sullivan, T. K. (2011). The many faces, features and outcomes of youth engagement. Journal of Youth Development, 6, 109-125.

Salusky, I., Larson, R. W., Griffith, A., Wu, J., Raffaelli, M., Sugimura, N., \& Guzman, M. (2014). How adolescents develop responsibility: What can be learned from youth programs. Journal of Research on Adolescence, 24, 417-430. doi: 10.1111/jora.12118

Shaw-Raudoy, K., \& McGregor, C. (2013). Co-learning in youth-adult emancipatory partnerships: The way forward? International Journal of Child, Youth and Family Studies, 3.1, 391-408.

Shier, H. (2001). Pathways to participation: Openings, opportunities, and obligations. Children and Society, 15, 107-11.

Sinha, M. (2015). Spotlight on Canadians: Results from the General Social Survey. Volunteering in Canada, 2004 to 2013. Ottawa, ON: Statistics Canada. Retrieved from http://www.statcan.gc.ca/pub/89-652-x/89-652-x2015003-eng.pdf

Smith, A., Peled, M., Hoogeveen, C., Cotman, S. \& the McCreary Centre Society (2009). A seat at the table: A review of youth engagement in Vancouver. Vancouver, BC: McCreary Centre Society.

Snow, K., \& S. H., K. S., K. J., D. O. A., \& M. P. (2013). Aspirations and belonging: Touchstones for the journey. International Journal of Child, Youth and Family Studies, 4, 381-390.

The Students Commission of Canada (2016). Who we are. Retrieved from: http://www.tgmag.ca/aorg/aboutusref_e.php

Taft, J. K., \& Gordon H. R. (2016). Intergenerational relationships in youth activist networks. In S. Punch \& Robert Vanderbeck (Eds.), Families, intergenerationality and peer group relations. Singapore: Springer. doi: 10.1007/978-981-4585-92-7_9-1

Treseder, P. (1997). Empowering children and young people: Training manual. London, England: Children's Rights Office and Save the Children.

Treseder, P., \& Crowley, A. (2001). Taking the initiative: Promoting young people's participation in decision-making in Wales. London, England: Carnegie Young People Initiative.

The United Nations. (1989). Convention on the Rights of the Child. Treaty Series, 1577, 3.

U.S. Bureau of Labor Statistics. (2016). Volunteering in the United States, 2015. Washington, DC: Author. https://www.bls.gov/news.release/volun.nr0.htm 
Youth-Adult Partnerships in Work with Youth

Vachon, W. \& McConnell, T. (in press). Allies, not accomplices: What youth work can learn from trans and disability movements. In P. Alldred, F. Cullen, K. Edwards, \& D. Fusco, (Eds.), The SAGE Handbook of Youth Work Practice. Thousand Oaks, California: SAGE Publications.

Wong, N. T., Zimmerman, M. A., \& Parker, E. A. (2010). A typology of youth participation and empowerment for child and adolescent health promotion. American Journal of Community Psychology, 46, 100-114. doi: 10.1007/s10464-010-9330-0

Zeldin, S. (2004). Preventing youth violence through the promotion of community engagement and membership. Journal of Community Psychology, 32, 623-641. doi: 10.1002/jcop.20023

Zeldin, S., Christens, B., \& Powers, C. (2013). The psychology and practice of youth-adult partnership: Bridging generations for youth development and community change. American Journal of Community Psychology, 51, 385-397. doi: 10.1007/s10464-012-9558-y

Zeldin, S., Krauss, S.E., Collura, J., Lucchesi, M., \& Sulaiman, A.H. (2014). Conceptualizing and measuring youth-adult partnership in community programs: A cross national study. American Journal Community Psychology, 54, 337-347. doi: 10.1007/s10464-014-9676.

Zeldin, S., Krauss, S. E., Kim, T., Collura, J., \& Abdullah, H. (2015). Pathways to youth empowerment and community connectedness: A study of youth-adult partnership in Malaysian after-school, cocurricular programs. Journal of Youth and Adolescence, 1-14. doi: 10.1007/s10964-015-0320-2

Zimmerman, M. A. (2000). Empowerment theory: Psychological, organizational and community levels of analysis. In J. Rappaport \& E. Seidman (Eds.), Handbook of community psychology (pp. 43-63). New York, NY: Plenum Press. 